\title{
Menos com menos dá menos, menos vezes menos dá mais: problemas de tradução?
}

\author{
Less with less gives less, fewer times less gives more: translation \\ problems?
}

\author{
Dailson Evangelista Costa ${ }^{1}$ \\ Mônica Suelen Ferreira de Moraes² \\ Marisa Rosâni Abreu Silveira ${ }^{3}$
}

\section{Resumo}

Este trabalho tem o objetivo de discutir alguns problemas encontrados na tradução de textos escritos em linguagem matemática para a linguagem natural, em situações de ensino e aprendizagem, em particular, destacando a adição, subtração, multiplicação e divisão com números positivos e negativos. Buscamos estudos em tradução sob a perspectiva de filósofos, matemáticos e educadores matemáticos com a finalidade de termos referenciais teóricos para analisarmos a tradução sob o ponto de vista pedagógico. Para isso, procuramos construir compreensões sobre o seguinte questionamento: por que os alunos confundem as operações, adição e subtração com multiplicação e divisão, entre números positivos e negativos? Os encaminhamentos metodológicos tomados partiram de apontamentos teóricos na perspectiva do rigor (GRANGER, 1989), do uso do simbolismo (WHITEHEAD, 1987), da episteme grega (LIZCANO, 1993), e sobretudo, sobre regras e acordos (SEGATTO, 2010). Os resultados das discussões teóricas apontam que a regra usual, menos vez menos dá mais, carrega, sutilmente, uma falta de rigor na tradução e que a regra é aceita devido ao fato de ser a única que mantém o resultado das operações realizadas, independentemente da maneira de se resolver. Percebemos, também, que existem alguns problemas de tradução da linguagem natural para a linguagem matemática e vice-versa.

Palavras-chave: problemas de tradução, operações com números positivos e negativos, linguagem matemática.

\section{Abstract}

This work has the objective of gathering some of its didactic texts in English into the language, in some instances of teaching and learning, in particular, highlighting, subtracting, multiplying and with positive and negative lots. We seek scholars in translation from the perspective of philosophers, mathematicians and mathematical educators with the purpose of having theoretical references to analyze a translation from the pedagogical point of view. For this, do companies need to acquire, improve, and subtract with multiplication and division, between positive and negative numbers? The methodological meanings taken from

\footnotetext{
${ }^{1}$ Universidade Federal do Tocantins | dailson_costa@uft.edu.br

2 Universidade Federal do Tocantins | monicamoraes@uft.edu.br

${ }^{3}$ Universidade Federal do Pará | marisabreu@ufpa.br
} 
theoretical points of view (GRANGER, 1989), the use of symbolism (WHITEHEAD, 1987), the Greek episteme (LIZCANO, 1993), and above all rules and agreements (SEGATTO, 2010). The results of the research are pointed out as usual rule of thumb, preferably, unlike what happens with a single formula of rigor in translation. way of solving it. We also noticed that there are some problems of translating the natural language into a mathematical language and vice versa.

Keywords: translation problems, operations with positive and negative numbers, mathematical language.

\section{Introdução}

Apresentamos, neste texto, algumas discussões sobre os problemas encontrados na tradução de textos escritos em linguagem matemática para a linguagem natural e viceversa, em situações de ensino e aprendizagem, em particular, destacando a adição, subtração, multiplicação e divisão com números positivos e negativos. Pretendemos discutir alguns aspectos que envolvem a regra usual da multiplicação $-\times-=+$, levando em consideração o rigor, o uso do simbolismo, a episteme grega e, sobretudo, as regras e acordos estabelecidos durante o processo de ensino e aprendizagem de matemática.

Como pergunta norteadora, buscamos investigar: Por que os alunos confundem as operações, adição e subtração com multiplicação e divisão, entre números positivos e negativos? Para tanto, apresentamos algumas implicações teóricas no que diz respeito ao rigor, ao uso do simbolismo, à episteme grega e sobre as regras e acordos tecidos na perspectiva de filósofos, sociólogos, matemáticos e educadores matemáticos. Posteriormente, destacamos uma análise de um livro didático, mostrando a maneira que os números negativos e as operações entre eles são apresentadas, no sétimo ano do Ensino Fundamental.

Para finalizarmos as reflexões aqui trazidas, atribuímos a justificativa do uso da regra de sinais ao Teorema de Hankel explicitado em Moretti (2012). Isto é, do ponto de vista didático, proporcionar situações em que os alunos percebam os possíveis resultados que podem ser encontrados ao realizar uma operação matemática, utilizando-se da regra convencional da multiplicação de sinais $(-x-=+$ ), e de uma suposta segunda regra, na qual $(-x-=-)$, operando de três maneiras distintas (eliminando os parênteses, distributividade pela direita e distributividade pela esquerda), pode contribuir para uma melhor compreensão das operações matemáticas básicas realizadas quando envolvem multiplicação, divisão, regras de sinais, levando em consideração alguns aspectos intrínsecos estabelecidos na tradução da linguagem natural para a linguagem matemática.

\section{O rigor da Matemática}

Giles Gaston Granger, na sua obra "Por um conhecimento filosófico", traz uma discussão sobre o rigor da matemática que vai nos permitir analisar, do ponto de vista teórico e filosófico, a questão que pretendemos investigar: por que os alunos confundem as operações, adição e subtração com multiplicação e divisão, entre números positivos e 
negativos? Para Granger (1989, p. 68) 4, "a procura do rigor parece inseparável da atividade Matemática".

No que se refere ao conhecimento: "parece-nos que não poderíamos nos orgulhar em conseguir caracterizar qualquer forma de conhecimento sem tê-la confrontado com o conhecimento matemático" (p. 67). Isto é, "se 'dois e dois são quatro' é seguramente o enunciado de um saber do qual ninguém sonharia contestar seriamente, a clareza, a adequação, a certeza" (p. 67).

Ainda segundo Granger (1989, p. 68), "O rigor é definido por Littré no quarto e sexto parágrafo de seu artigo como: $1^{\circ}$. O caráter de um raciocínio ao qual o intelecto não pode resistir; $2^{\circ}$. Uma "grande exatidão", uma grande severidade na aplicação das regras". No que se refere ao raciocínio o "Rigor é propriedade intrínseca dos sinais, e seus sistemas e de sua manipulação". Já "a exatidão supõe a análise tão desenvolvida quanto possível de um complexo; ela pertence, dentro do uso restrito que nós queremos caracterizar sua oposição ao rigor, aos dois campos semânticos da verdade da precisão" (GRANGER, 1989, p. 69).

Granger (1989, p. 69) entende a palavra rigor por três temas:

$1^{0}$ - A referência a regras constrangedoras, cuja estrita observação garante a um pensamento progressivo certas propriedades desejadas, conferindothe, nos casos extremos, uma forma canônica rígida.

$2^{\circ}$ - Uma obrigação de conclusão que interdita apelar para elementos estrangeiros, com a atribuição de separar, para superar através de expedientes ad hoc os obstáculos que vão de encontro ao encadeamento de nossos pensamentos.

$3^{\circ}$ - Uma disposição constante para reconhecer e explicitar todos os pressupostos dos procedimentos, em particular os que dissimulam as evidências aparentes.

Posteriormente, refere-se à seguinte citação: "Uma teoria filosófica, em sua forma completa e perfeita, é uma teoria matematizada" (On Philosophical Method, p. 128 apud GRANGER, 1989, p. 70). E afirma que a linguagem contribui de fato a fixar a relação de um conteúdo a uma fórmula e que a formalização e a axiomatização são as operações preparatórias indispensáveis.

Não há, de nenhum modo, para a matemática pura, uma linguagem certa, isto é, uma linguagem que, na comunicação, evitaria os maus entendidos e que, como um meio mnemotécnico, premuniria contra os erros (isto é, as confusões de entidades matemáticas distintas) (mathematische Wissenschaft und Sprache, 1998, em Collected Works, t. I, p. 417, apud GRANGER, 1989, p. 92).

Reforçando, "a matemática, enquanto conhecimento rigoroso por excelência, nos revelou alguns traços de um certo ideal do conhecimento, ao qual todo saber pode ser, se não medido, pelo menos comparado (GRANGER, 1989, p. 94).

\footnotetext{
${ }^{4}$ Para evitarmos repetições nas referências das citações diretas, apenas será posto os números das páginas referentes às partes dos textos, visto que as reflexões apontadas neste tópico são de Granger (1989).
} 
Assim sendo, no próximo tópico, apresentam-se algumas dificuldades vivenciadas historicamente entre os povos ocidentais e orientais, no que diz respeito da aceitação dos números negativos.

\section{A episteme grega e os limites da abstração}

O matemático, filósofo e sociólogo Emmánuel Lizcano, em "Episteme Grega e os limites da abstração", parte da obra "Imaginario colectivo y creación matemática: La construcción social del número, el espacio y lo imposible en China y en Grecia", apresenta certos traços da episteme grega que se manifestaram nesses espaços (China e Grécia) e determinaram a impossível emergência de negatividade partindo de dois pressupostos: a) uma certa concepção de espaço de representação como espaço extenso, com o consequente prérequisito da determinação de perceptibilidade sensível para objetos, procedimentos e determinações das condições em que a solução para um problema existente é representável; b) uma mentalidade que procede por abstração do que é mostrado pelo senso comum, isto é, um processo de ordenação do mundo, e do conhecimento, regido pela determinação progressiva de gêneros e espécies. Isso acarretou na dificuldade de compreender os números negativos que, posteriormente, implicaria na dificuldade de compreender as operações com números negativos (adição, subtração, multiplicação e divisão), foco de estudo desta investigação (LIZCANO, 1993).

Na obra apresentada, Lizcano (1993) faz uma distinção entre o pensamento grego (pensamento ocidental) e o pensamento chinês (pensamento oriental). Para ele, os chineses, em síntese, aceitavam mais facilmente a existência de possíveis conhecimentos, mesmo não podendo teorizá-los. Um exemplo disso, e que nos possibilita refletir sobre a questão norteadora desta investigação, é o caso da aceitação dos números negativos, que ele aponta fortemente nos limites da abstração. Para os gregos era impossível conceber números negativos, visto que geometricamente (em termos de medida) não tinha como representá-los (a não ser na reta real) no espaço real.

Para complementar as discussões teóricas e posteriormente ter consubstancialmente suporte para analisarmos a questão de investigação aqui apresentada, é necessária uma breve discussão sobre o uso do simbolismo, visto que as operações que envolvem a adição, subtração, multiplicação e divisão entre números positivos e negativos, são expressas em termos de um simbolismo próprio da matemática.

\section{Uso do simbolismo}

Segundo Whitehead (1987) $)^{5}$ o comportamento da humanidade perante o simbolismo é marcado por uma relação de atração e repulsa. Para o autor, são três os motivos principais para a repulsa do simbolismo, a saber: a inteligência prática; o desejo teorético de penetrar nos fatos últimos; e os impulsos críticos e irônicos. No que se refere ao primeiro, ele afirma que "os homens realistas querem factos e não símbolos" (p. 55). Já no segundo, ele aponta

\footnotetext{
${ }^{5} \mathrm{Na}$ intenção de evitarmos repetições nas citações diretas, e como as ideias são de Whitehead (1987), apenas nos referenciaremos aos números das páginas nas suas citações neste tópico.
} 
que o intelecto teorético "põe de lado os símbolos como simples quimeras, que a razão exige como sua propriedade própria" (p. 55). E, por último, tece que "os críticos irônicos das tolices da humanidade prestaram um serviço notável ao arrumarem os tarecos de cerimônias inúteis que simbolizam as fantasias degradantes de um passado selvagem" ( $p$. 55). Para ele, os três motivos que repulsaram o simbolismo contribuíram para a sociedade no sentido de entender que por mais que se tente expulsar o simbolismo, este sempre se fará presente devido ser inerente a vida humana, afirmando que até mesmo a linguagem é um simbolismo.

Desse modo, para Whitehead (1987), o simbolismo é a forma que a humanidade encontrou para se expressar, retirando alguns elementos da experiência e relacionando-os entre si. Para ele, "o objetivo do simbolismo é realçar a importância do que é simbolizado" (p. 57). Isto é, o simbolismo torna possível o pensamento conexo, exprimindo-o, enquanto dirige ao mesmo tempo a ação. A sociedade adquiriu a eficácia dos símbolos imediatamente preservadores do bem público e do ponto de vista individual, sendo a linguagem uma forma particular do simbolismo e, as palavras e frases, além da simples indicação de significado, veiculam um poder sugestivo envolvente e uma eficácia emocional.

Com efeito, Whitehead (1987) ainda afirma que ao examinarmos uma sociedade, descobrimos que um agente ativo importante é o nosso vasto sistema de simbolismo herdado. A auto-organização da sociedade depende de símbolos comumente difundidos que evocam ideias comumente espalhadas e indicando, ao mesmo tempo, ações comumente entendidas. Afirma que "os homens livres obedecem às regras que eles próprios fizeram" (p. 73) e complementa:

A arte da sociedade livre consiste, primeiro, na manutenção do código simbólico; e, em segundo lugar, na intrepidez para o rever, a fim de garantir que o código sirva as finalidades que satisfazem uma razão ilustrada. As sociedades que não podem combinar o respeito pelos seus símbolos com a liberdade de revisão devem, em última análise, entrar em decadência, ou em virtude da anarquia, ou por causa da lenta atrofia de uma vida abafada por sombras inúteis (WHITEHEAD, 1957, p. 74).

Agora, veremos que o uso desse simbolismo está estritamente interligado às regras e acordos.

\section{Sobre regras e acordos}

Segatto $(2010)^{6}$ identifica, a partir das contribuições de Wittgenstein, dois vetores presentes na relação entre regra e aplicação: "um que vai da regra a sua aplicação, que se poderia chamar, fazendo um paralelo com a filosofia kantiana, de determinante, e outro que vai da aplicação à regra, que poderia se chamar, mantendo o paralelo, de reflexionante" (p. 137) (ver Figura 1). A íntima relação entre esses dois aspectos revela o pensamento de Wittgenstein sobre o tratado em questão, pois, tanto as regras quanto a sua aplicação são normativas e as suas interpretações supõe regularidades que se dão no

\footnotetext{
${ }^{6}$ Para evitarmos repetições nas referências às citações, apenas destacaremos os números das páginas citadas nesta obra e que são usadas nas citações diretas.
} 
acordo das definições e no acordo dos juízos. "Uma regra só pode ser aplicada e sua aplicação só pode ser considerada correta porque a regra e sua aplicação são parte de uma prática normativa que supõe uma regularidade no resultado, regularidade esta que é expressa no acordo, nas definições e no acordo nos juízos" (p. 137). Daí, "para que possa me parecer que a regra tenha produzido todas as suas consequências de antemão, elas devem ser evidentes a mim. Tão evidentes quanto é evidente para mim chamar essa cor de 'azul' (critério para que isso seja 'evidente' a mim)" (WITTGENSTEIN, 2001, § 238 apud SEGATTO, 2010, p. 137).

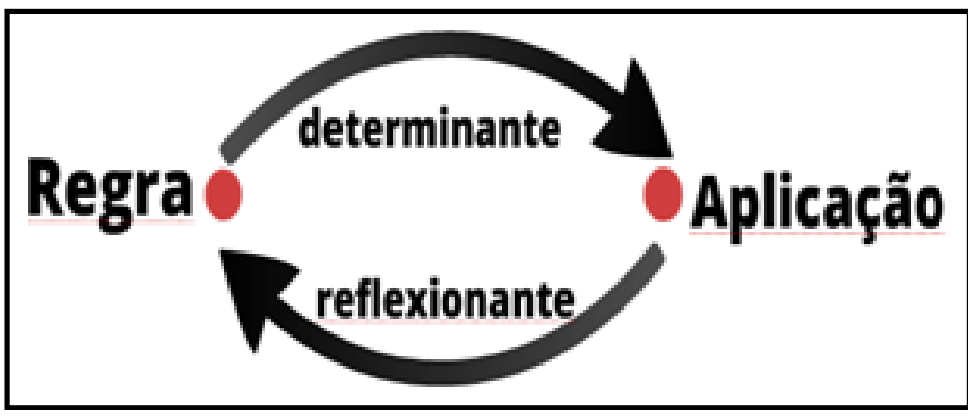

Figura 1: vetores presentes na relação entre regra e aplicação.

A relação interna entre a regra e uma aplicação concreta da regra é respondida pela dimensão determinante, já a relação que vai do acordo nos juízos ao acordo nas definições é respondido pela dimensão reflexionante.

Esta relação permitirá compreender melhor a relação entre linguagem e mundo, temática fundamental na filosofia wittgensteiniana. Ou seja, "quando sigo uma regra 'não escolho'. E 'não escolho', cumpre dizer, porque não há escolha se não há alternativas" (p. 138). Isto é, precisa saber o que a regra prescreve e o que é uma aplicação correta da regra. Ressalta que ao determinar o sentido de uma regra, exclui possibilidades de escolha, pois saber o que é prescrito por esta regra significa saber aplicá-la corretamente.

O que permite a identificação de uma formulação de regra qualquer, sua expressão, como formulação de uma determinada regra é não apenas a discriminação do que a regra prescreve - que se deve agir de tal maneira -, mas também a discriminação do modo como se deve aplicá-la (SEGATTO, 2010, p. 142).

Segatto (2010) complementa afirmando que "além da concordância (Übereinstimmung) entre regra e suas aplicações deve haver um acordo (Übereinstimmung) entre aqueles que aplicam a regra" (p. 143).

Digamos que os homens, para se entenderem uns aos outros, têm que concordar entre si a respeito dos significados das palavras. Mas o critério para esse acordo não é apenas um acordo em relação às definições, por exemplo, definições ostensivas, - mas também um acordo nos juízos. É fundamental para o entendimento que nós concordemos em um grande número de juízos (WITTGENSTEIN, 1984 § 39 apud SEGATTO, 2010, p. 145).

Segatto (2010) afirma, conforme Wittgenstein, que os homens concordam na linguagem "não por opiniões", mas, que isto se deve à forma de vida. Explicita que o consenso está em agirmos do mesmo modo: andar, comer, beber, jogar, são atividades. Da mesma forma, ordenar, perguntar, narrar, calcular devem-se a fatos históricos de natureza 
antropológica (culturais e sociais). Destaca que acordos são fundamentais nas definições e que a regra prescrita e seu sentido dependem de juízos e regularidades nela contida. Conclui a reflexão sobre regras e acordos e ressalta que a linguagem não se justapõe para representar o mundo, mas que é parte dele, é um aspecto do nosso agir.

O acordo nas definições é fundamental, pois é condição necessária, embora não seja suficiente, para que uma formalização de regra qualquer seja reconhecida como a formalização de uma determinada regra ou que um padrão qualquer seja reconhecido como o padrão de uma determinada unidade de medida. Por outro lado, o acordo nos juízos é igualmente fundamental, pois é condição para a constituição do método de aplicação de uma formulação de regra ou de um padrão de medida (SEGATTO, 2010, p. 145).

Em outras palavras, além da discriminação do que a regra prescreve, isto é, seu sentido, dependendo de um acordo nas definições, também é necessário a discriminação do modo como se deve aplicá-la, de acordo com os juízos e da regularidade presente. "No caso das regras, a regularidade e o acordo no agir, que se desenrola no mundo, é condição necessária para que elas possam ser instituídas" (p. 148).

Para continuarmos os encaminhamentos traçados e possibilitar nossas análises, evidenciaremos, no próximo tópico, um estudo de como são apresentadas as operações com números positivos e negativos em um determinado livro didático escolhido aleatoriamente.

\section{Um estudo da organização do livro didático}

Na análise do livro didático de Ribeiro e Soares (2006), do sétimo ano do Ensino Fundamental, em especial ao tópico que trata das operações (adição, subtração, multiplicação e divisão) com números positivos e negativos, intitulado "Os números positivos e negativos", destacamos a seguinte organização: inicialmente, o referido livro apresenta a seguinte operação em uma calculadora: $74-154=-80$, e pergunta: em sua opinião, qual o significado do símbolo (-) na frente do número 80 mostrado no visor da calculadora? Em seguida, este tópico é dividido em 7 (sete) subtópicos que seguem a seguinte sequência: (1) números positivos e negativos; (2) os números inteiros na reta numérica; (3) comparando números positivos e negativos; (4) adição com números positivos e negativos; (5) adição e subtração com números positivos e negativos; (6) multiplicação com números positivos e negativos e; (7) divisão com números positivos e negativos.

No subtópico (1), os números positivos e negativos são apresentados de quatro maneiras diferentes: a partir de exemplos e ilustrações envolvendo temperatura em graus ${ }^{\circ} \mathrm{C}$. Depois, são expressos também como linha cronológica do tempo (-8400 a. C. à +1997). Posteriormente como extrato bancário (saldos positivos e negativos, transações). E, por último, com exemplos envolvendo altitude positiva e negativa, considerando o nível do mar como referência.

No subtópico (2), os números inteiros na reta numérica são apresentados basicamente na reta numérica, entretanto, de várias perspectivas. A primeira é dada ênfase no sentido positivo e negativo da reta. Em seguida é exposto o sistema solar e colocando os planetas na reta numérica segundo suas temperaturas em ${ }^{\circ} \mathrm{C}$. Posteriormente são exibidos os números simétricos e opostos. 
No que diz respeito ao subtópico (3) comparando números positivos e negativos, mais uma vez, usa-se exemplos de temperaturas em graus ${ }^{\circ} \mathrm{C}$ e representações na reta.

Já no subtópico (4) adição com números positivos e negativos, faz-se uso de exemplos que envolvem lucro e prejuízo de uma rede de supermercado e, posteriormente, apresentase as propriedades: comutativa; elemento neutro; e associativa.

Se tratando do subtópico (5) adição e subtração com números positivos e negativos, mais uma vez são trazidos exemplos envolvendo temperatura, e exemplos que abordam as diferenças dos horários no planeta. Nada tão diferente dos subtópicos anteriores.

Já o subtópico (6) multiplicação com números positivos e negativos, inicialmente é apresentado com o "jogo de perguntas e respostas", depois novamente a representação na reta como registro do jogo, e um "jogo das setas" é utilizado para trabalhar questões envolvendo multiplicação. Depois de alguns exercícios, apresenta-se as seguintes regras:

Regra 1: "Em uma multiplicação de dois fatores em que um dos fatores é um número positivo e outro, um número negativo, o produto é um número negativo".
Ex.: a) $(+5) \times(-7)=-35$
b) $(-1) \times 4=-4$
c) $(-3,4) \times(8)=-27,2$

Regra 2: "Em uma multiplicação de dois fatores em que ambos são números negativos, o produto é um número positivo".

Ex.: a) $(-2) \times(-7)=+14 \quad$ b) $(-9) \times(-5,7)=+51,3 \quad$ c) $(-7) \times(-11)=+77$

Quadro 1: Regra 1 e Regra 2 apresentadas no livro didático.

Depois disso, mais exercícios são propostos.

Assim como foi apresentado em (6) multiplicação com números positivos e negativos, (7) divisão com números positivos e negativos também é apresentado como regras. Mas, são apresentados dois problemas iniciais: ${ }^{\circ}$ ) Pensei em um número, dividi por 4 e obtive -8 como resultado. Em que número pensei? $2^{\circ}$ ) Qual é o número que, ao ser dividido por -7 , resulta -28 ?

As regras apresentadas são:

Regra 3: "Em uma divisão de dois números com sinais diferentes, o quociente é um número negativo".

Ex.: a) $(-8) \div(+2)=-4$

b) $(25) \div(-5)=-5$

Regra 4: "Em uma divisão de dois números com sinais iguais, o quociente é um número positivo".

Ex.: a) $(-16) \div(-8)=+2$

b) $(+8,6) \div(+2)=+4,3$

Quadro 2: Regra 1 e Regra 2 apresentadas no livro didático.

Contudo, com base nas nossas experiências em sala de aula, percebemos que situações parecidas com as do quadro 3, acontecem.

\begin{tabular}{|l|l|l|}
\hline A. $(-2) \times(-5)=-10$ & F. $(-2)+(-5)=10$ & K. $(-2)-(-5)=7$ \\
\hline B. $(-2) \times(5)=10$ & G. $2 \times(-5)=10$ & L. $(-2)+(-5)=-10$ \\
\hline C. $-3+5=8$ & H. $-3+5=-2$ & M. $(-3)-(-5)=-8$ \\
\hline D. $\frac{-8}{2}=4$ & I. $\frac{-8}{-2}=-4$ & N. $\frac{8}{-2}=4$ \\
\hline E. $\frac{-10}{-2}=-5$ & J. $\frac{-10}{2}=5$ & O. $\frac{10}{-2}=5$ \\
\hline
\end{tabular}

Quadro 3: exemplos de supostos erros cometidos por alunos.

Isto é, equívocos na tradução da linguagem natural (estabelecida nas regras) em relação à linguagem matemática (aritmética) são encontrados quando os alunos se deparam com situações parecidas com estas mostradas no quadro 3 e, consequentemente, 
em uma outra linguagem matemática (algébrica) que envolva, por exemplo, equações, inequações, os mesmos equívocos frequentemente acontecem. A pergunta é: por que isso acontece? Na intenção de construirmos algumas compreensões a respeito deste questionamento, além de já termos trazido algumas discussões teóricas para que possamos nos situar, assim como a breve análise do livro didático, apresentaremos, em seguida, a questão norteadora desta investigação em forma de tópico.

\section{Por que os alunos confundem as operações, adição e subtração com multiplicação e divisão, entre números positivos e negativos?}

Para Moretti (2012), a explicação do porquê da regra dos sinais está no Teorema de Hankel. O autor aponta que esta regra é apresentada por Diofanto de Alexandria há muito tempo e que somente em 1867 ela foi demonstrada por Hermann Hankel (1839-1873), como sendo a única que possui a vantagem de satisfazer a distributividade à esquerda e a distributividade à direita. Assim sendo, com a demonstração feita por Hankel, do ponto de vista matemático, o resultado $(a-b) \times(c-d)=a c-a d-b c+b d$, consequência do uso da regra "menos multiplicado por menos é mais e menos multiplicado por mais é menos", não causa nenhuma dificuldade ou estranheza. Entretanto, como sabemos, do ponto de vista didático e pedagógico, essa situação ainda se encontra obscura, principalmente quanto ela ocorre em sala de aula.

Em síntese, Moretti (2012) apresenta alguns estudos baseados na perspectiva de ensino dessa regra (regra dos sinais) na ideia de congruência semântica ${ }^{7}$ e no princípio de extensão ${ }^{8}$ em matemática. Faz uma abordagem histórica do surgimento dos números negativos e das operações com os mesmos, assim como aponta alguns indícios de como eles aparecem nos Parâmetros Curriculares Nacionais (PCN) e National Council of Teachers of Mathematics (NCTM). Em seguida, apresenta os principais modelos (quatro no total) que explicam a regra dos sinais para a multiplicação, inspirados no desenvolvimento histórico dos números relativos. Os modelos são: modelo de área baseados na relação de Diofanto de Alexandria; modelos didáticos baseados na ideia de balanço: o modelo comercial; modelos didáticos que se baseiam no prolongamento da reta numérica dos naturais; e modelo do tipo lógico. De maneira sintética, são os mesmos evidenciados durante a análise no livro didático feito no tópico anterior e que, segundo as análises feitas por Moretti (2012),

\footnotetext{
7 "Duas expressões podem ter o mesmo sinônimo ou referencialmente equivalentes (elas podem 'dizer a mesma coisa', elas podem ser verdadeiras ou falsas conjuntamente) e não serem semanticamente congruentes: neste caso há um custo cognitivo importante para a compreensão (DUVAL, 1988, p. 8 apud MORETTI, 2012, p. 705). Para maiores informações, conferir fonte citada.

${ }^{8}$ Caraça (1951, p. 9, 10 apud MORETTI, 2012, p. 694) denomina de princípio de extensão: [...] o homem tem tendência a generalizar e estender todas as aquisições do seu pensamento, seja qual for o caminho pelo qual essas aquisições se obtêm, e a procurar o maior rendimento possível dessas generalizações pela exploração metódica de todas as suas consequências. (CARAÇA, 1951, p. 10). Para maiores informações, conferir fonte citada.
} 
todos apresentam possibilidades de causarem obstáculos didáticos ${ }^{9}$. Entretanto, a escolha pelo Teorema de Hankel, que seria a explicação da regra, segundo Moretti (2012), ultrapassa a capacidade de compreensão do aluno do ensino fundamental. A pergunta é: o que fazer?

Moretti (2012) cita os estudos de Glaser (1981) que identificou diversas dificuldades relacionadas à compreensão dos números relativos: inabilidade em manipular e dar sentido às quantidades negativas; prolongamento da reta numérica para incluir os negativos; a ambiguidade dos dois zeros (medida e origem); dificuldade de superar o sentido concreto, em oposição ao sentido formal, da noção de negativo; a busca de um modelo explicativo unificador ${ }^{10}$.

A partir de análises sobre o Teorema de Hankel, Moretti (2012) apresenta alguns indicativos de como explicá-lo de maneira mais didática.

Consideremos a regra dos sinais usual para adição e a regra dos sinais para a multiplicação definida em cada uma das colunas do quadro 4, que será aplicada a um exemplo construído com o objetivo de explorar as distributividades à direita e à esquerda:

\begin{tabular}{|c|c|}
\hline Regra usual & Regra 2 \\
\hline$+\times+=+$ & $+\times+=+$ \\
\hline$+\times-=-$ & $+\times-=-$ \\
\hline$-\times+=-$ & $-\times+=-$ \\
\hline$-\times-=+$ & $-\times-=-$ \\
\hline
\end{tabular}

Quadro 4: A regra usual e outra regra de sinais

Observemos que na Regra 2 supomos " $-\times-=-$ ", o que é diferente do que está definido na regra usual. Apliquemos estas duas regras à expressão $(1-3) \times(-5+1)$, conforme o quadro 5:

\begin{tabular}{|l|l|l|}
\hline \multicolumn{2}{|c|}{ Modelo baseado no Teorema de Hankel } \\
\hline \multicolumn{2}{|c|}{ Regra Usual } & \multicolumn{1}{c|}{ Regra 2 } \\
\hline $\begin{array}{l}\text { Elimine ambos os } \\
\text { parênteses }\end{array}$ & $\begin{array}{l}=-2 \times-4 \\
=+8\end{array}$ & $\begin{array}{l}=-2 \times-4 \\
=-8\end{array}$ \\
\hline & $=-2 \times(-5+1)$ & $=-2 \times(-5+1)$ \\
Eliminando o parêntese à & $=-2 \times(-5)-2 \times(+1)$ & $=-2 \times(-5)-2 \times(+1)$ \\
esquerda e usando & $=+10-2$ & $=-10-2$ \\
distributividade & $=+8$ & $=-12$ \\
\hline & $=(1-3) \times-4$ & $=(1-3) \times-4$ \\
Eliminando o parêntese à & $=1 \times(-4)-3 \times(-4)$ & $=1 \times(-4)-3 \times(-4)$ \\
direita e usando a & $=-4+12$ & $=-4-12$ \\
distributividade & $=+8$ & $=-16$ \\
\hline
\end{tabular}

Quadro 5: comparação entre duas regras de sinais para a multiplicação ${ }^{12}$

\footnotetext{
${ }^{9}$ Não esmiuçaremos esses modelos por não ser o foco central deste trabalho, mas, caso o leitor tenha interesse, conferir: MORETTI, 2012.

${ }^{10}$ Caso o leitor queira se aprofundar sobre esses modelos, conferir: GLASER, 1981

${ }^{11}$ Quadro retirado de: MIORETTI, 2012.

12 Quadro retirado de: MORETTI, M. T., 2012.
} 
Ou seja, o quadro 5 mostra claramente que, com a regra usual, os resultados obtidos são os mesmos, tanto eliminando os parênteses simultaneamente ou eliminando os parênteses à esquerda e usando a distributividade, quanto eliminando os parênteses à direita e usando a distributividade. Já usando a suposta regra 2, percebe-se que nas três maneiras de se resolver, os resultados obtidos são diferentes. Portanto, Moretti (2012) defende que este seja um dos aspectos que podem contribuir para uma melhor compreensão das regras de sinais, do ponto de vista didático, assim como a ideia de princípio da extensão, ausente do ensino fundamental e médio, deve guiar o ensino da regra dos sinais:

Para o campo aditivo, o modelo do prolongamento dos números naturais para a reta numérica dos inteiros como sugerido em (BRASIL, 1998b) que não deixa de ser uma aplicação do princípio de extensão. A reta numérica dos relativos é um suporte importante na resolução de problemas neste campo. Para o campo multiplicativo, o modelo baseado no Teorema de Hankel, que tem por base a ideia do princípio da extensão da propriedade da distributividade dos números positivos para o caso dos números negativos. A subtração será trabalhada neste campo para que as relações do tipo "a - (-b)" e "a - (+b)" possam ser tratadas (MORETTI, 2012, p. 711).

E conclui afirmando que: "se quisermos manter o mesmo resultado, independentemente do modo de calcular, devemos eliminar a possibilidade de que a regra para a multiplicação seja definida, por exemplo, conforme a Regra 2" (MORETTI, 2012, p. 711). Portanto, temos que optar pela regra usual, como sendo a única que se mantém os resultados.

Assim, refletindo sobre os apontamentos teóricos dissertados nesta investigação, sobre a análise do livro didático e, sobretudo, com a justificativa apontada por Mioretti (2012) para a regra dos sinais, identificamos alguns fatores que influenciam no processo de ensino e aprendizagem das operações com números negativos e positivos, e que contribuem para a justificativa exposta pelo Teorema de Hankel, fatores estes ligados a problemas de tradução. Isto é, aspectos que vão além do matemático, do didático, do pedagógico, influenciam nas dificuldades apresentadas, aspectos estes relacionados com a própria linguagem.

\section{Menos com menos, SOMO. Menos vezes menos, MULTIPLICO!}

Apresentam-se agora as seguintes afirmações: (1) menos com menos dá menos! E, (2) menos vezes menos dá mais! Assim sendo, poderíamos dizer que: (3) menos com menos é igual a menos dois. $E_{1}(4)$ menos vezes menos é igual a um.

Em notação simbólica, podemos expressar da seguinte maneira:

$$
\begin{aligned}
& \text { (1) }(-) \operatorname{com}(-) \text { dá }(-) \Leftrightarrow(-)+(-)=-(3) \\
& \text { (2) }(-) \times(-) \text { dá }(+) \Leftrightarrow(-) \times(-)=+(4)
\end{aligned}
$$

Quadro 6: Notação. 
Ou seja, em (1) o "com", matematicamente, dá ideia de somar, juntar, acrescentar, comparar. E, em (2), o " $x$ " é a própria multiplicação. Sendo assim, poderíamos reescrever (1) e (2) da seguinte maneira (tomando o número 1 como unidade de medida):

$(-) \operatorname{com}(-)$ dá $(-) \Leftrightarrow(-)+(-)=-$
$\Rightarrow(-1)+(-1)=2 \cdot(-1)=-2$
$(-) \times(-)$ dá $(+) \Leftrightarrow(-) \times(-)=+$
$\Rightarrow(-1) \times(-1)=+1$

Quadro 7: Notação.

Com efeito, considerando a linguagem acima, percebe-se que as afirmações (1.1) e (2.1), derivadas de (1) e (2), simultaneamente, são verdadeiras. Isto é, estamos compreendendo que, na tradução da linguagem matemática (quando o professor apresenta a regras dos sinais por meio da simbologia matemática) para a linguagem natural (quando o professor explica a regra por meio de palavras), existem problemas que são inerentes à tradução, porém, muitas vezes o professor não percebe. Assim, quando os alunos estão calculando, utilizando-se das operações com adição e subtração, os mesmos confundem as regras quando os cálculos estão em outro contexto, nas operações de multiplicação e divisão.

Evidenciaremos, agora, alguns aspectos que influenciam na tradução de textos matemáticos baseados nos autores abordados nesta investigação.

\section{O rigor, a episteme, o uso do simbolismo, as regras e acordos estabelecidos}

Com tudo que foi exposto até o momento, é perceptível que alguns aspectos relacionados à linguagem matemática, estabelecida na regra usual (jogos de sinais), estão entrelaçados. Isto é, o rigor (GRAGER, 1989), posto na regra usual, mantendo sempre o mesmo resultado, independentemente da maneira escolhida para resolver a operação (como mostrado no quadro 5), é um aspecto relevante que contribui na explicação trazida por Moretti (2012).

Outro aspecto é o uso do simbolismo (WHITEHEAD, 1987). As operações estabelecidas, os sinais, os números, são traços de uma simbologia própria da matemática e expressa, numa linguagem matemática, o significado rigorosamente da regra usual mostrada por Moretti (2012).

Para tanto, outro fator que se mostra evidente na explicação da regra dos sinais são as regras e acordos (SEGATTO, 2010) que estão implicitamente imbricadas na regra usual escolhida para operar na multiplicação entre números negativos. Números estes historicamente difíceis de aceitar, de operar, apontado pelos limites da abstração (LIZCANO, 1993). 


\section{Algumas considerações}

A matemática apresenta sua linguagem própria, revelada pelo rigor, por seus simbolismos, regras e acordos estabelecidos historicamente. As características também estão presentes quando o aluno lida com operações com números positivos e negativos. Abordagens metodológicas quando não contemplam o rigor necessário, podem contribuir mais ainda para a dificuldade apresentada pelos alunos em relação ao saber a ser ensinado e compreendido. Assim, as reflexões aqui trazidas indicam alguns fatores que possivelmente influenciam na aprendizagem das operações com números negativos. Desse modo, as contribuições apontadas por Moretti (2012) provavelmente terá efeito positivo em relação aos aspectos didáticos e pedagógicos e, principalmente, em relação à linguagem matemática que explica a regra usual do jogo de sinais.

Os resultados das discussões apontam que a regra usual, menos vez menos dá mais, carrega alguns aspectos de natureza das perspectivas apontadas e que esta regra é aceita devido ao fato de ser a única que mantém o resultado das operações realizadas, independentemente da maneira de se resolver.

Para finalizarmos as reflexões aqui realizadas, trazemos, novamente, a questão norteadora desta investigação: Por que os alunos confundem as operações, adição e subtração com multiplicação e divisão, entre números positivos e negativos? Defendemos que as dificuldades apresentadas na aprendizagem estão intimamente ligadas aos possíveis problemas de tradução. Isto é, aspectos que vão além do matemático, do didático, do pedagógico, influenciam nas dificuldades apresentadas, aspectos estes relacionados com a própria linguagem materna.

\section{Referências}

BRASIL. Parâmetros curriculares nacionais: Matemática (5a a $8^{a}$ séries). Secretaria de Educação Fundamental. Brasília: MEC/CEF, 1998b.

GLAESER, G. Epistemologie des nombres relatifs. Recherches em Didactique des Mathématiques, Grenoble, v. 2.3, p. 303-546, 1981.

GRANGER, Gilles-Gaston. O rigor da matemática. In: GRANGER, Gilles-Gaston. Por um conhecimento filosófico. São Paulo: Perspectiva, Ed. Papirus, p. 67-95, 1989.

HEBECHE, Luiz. A revelação do aspecto. In: HEBECHE, Luiz. O mundo da consciencia: o ensaio a partir da filosofía da psicología de L. Wittgensteins. Porto Alegre: EDIPUCRS, p. 93$114,2002$.

LIZCANO, Emmánuel. La episteme griega o los limites de La abstracción. In: LIZCANO, Emmánuel. Imaginario colectivo y creación matemática: La construcción social del número, el espacio y lo imposible en China y en Grecia. Barcelona: Gedisa Editorial, p. 149-208, 1993.

MORETTI, M. T. A regra dos sinais para a Multiplicação: ponto de encontro com a noção de congruência semântica e o princípio de extensão em matemática. In: Bolema: Rio Claro, SP, v. 26, n. 42B, p. 691-714, abr. 2012.

RIBEIRO, J.; SOARES, E. Construindo consciências: matemática. 1. ed. São Paulo: Scipione, 2006 (6 $6^{\mathrm{a}}$ série do ensino fundamental). 
SEGATTO, A. I. Sobre regras e acordos. In: MORENO, Arley R (Org.). Wittgenstein: Certeza? Campinas: UNICAMP, Centro de lógica, Epistemologia e História da Ciência, v. 58, p. 137149, 2010.

WHITEHEAD, Alfred North. Usos do simbolismo. In: WHITEHEAD, Alfred North. Simbolismo: o seu significado e efeito. Ediç̧̃es 70, p. 55-74, 1987. 